\title{
LESIONES DEPORTIVAS OSTEOCARTILAGINOSAS EN EL NIÑO Y ADOLESCENTE
}

\author{
Dra. Georgette Pose L.
}

Servicio de Radiología Clínica Alemana Santiago. Servicio de Radiología Hospital San Juan de Dios.

\begin{abstract}
Lesions affecting bone and cartilage are common clinical conditions in children and teenagers during sport related activities. This article reviews the $X$-ray, ultrasound, CT and MRI findings in these pathologic conditions.
\end{abstract}

Key words: Bone, Sport, Stress.

Resumen: Las lesiones provocadas por la práctica deportiva han aumentado significativamente. Esta revisión enfatiza las lesiones osteocartilaginosas que se producen especial o exclusivamente en niños y adolescentes, cuyo diagnóstico hasta hace algunos años era clínico y la contribución de las imágenes se limitaba a estudios radiológicos simples. Los avances de otras técnicas, especialmente el ultrasonido y la resonancia magnética, han llegado a ser actualmente el método primario de elección ante la sospecha o evidencia clínica de una lesión de partes blandas u osteocartilaginosas.

Palabras claves: Deporte, Estrés, Hueso.

\section{Introducción}

Las actividades deportivas competitivas en los niños y adolescentes han aumentado considerablemente y con ello las lesiones musculoesqueléticas por esta causa. Por otra parte, el avance de técnicas de imagen como el ultrasonido (US) y la resonancia magnética (RM), ha permitido una mejor evaluación y manejo de ellas, dependiendo el éxito terapéutico de un diagnóstico oportuno, detección de complicaciones del tratamiento y rehabilitación $\operatorname{adecuada}^{(1)}$.

Las lesiones deportivas en este grupo de edad difieren de aquellas del adulto, dado que existen factores anatómicos propios relacionados con el crecimiento y desarrollo ${ }^{(2,3)}$. Músculos, tendones,

Pose G. Lesiones deportivas osteocartilaginosas en el niño y adolescente. Rev chil Radiol 2005; 11: 91 - 100.

Correspondencia: Dra. Georgette Pose L.

Clínica Alemana. Vitacura 5951. Santiago de Chile. ligamentos y cápsulas articulares se desarrollan en respuesta al crecimiento óseo. El hueso crece más rápido que la unidad musculotendínea que lo rodea, produciéndose una disminución de la flexibilidad. Esto, en combinación con la capacidad de los niños para realizar grandes esfuerzos físicos y sostener niveles extremos de actividad, produce un desbalance que predispone a lesiones ${ }^{(4)}$. Además la relativa debilidad del cartílago a nivel de la fisis, apófisis y superficies epifisiarias, las hacen más vulnerables, particularmente durante el período de rápido crecimiento ${ }^{(5)}$.

Las lesiones deportivas pueden ser provocadas por trauma directo, indirecto o por sobreuso, estas últimas producidas por una actividad musculoesquelética repetitiva, con sobrecarga de estructuras normales ${ }^{(6)}$. Factores predisponentes son el entrenamiento inadecuado, correr en superficies duras y el uso de calzado deportivo inadecuado( ${ }^{(7)}$.

Esta revisión enfatiza las lesiones deportivas osteocartilaginosas que se producen especial o exclusivamente en niños y adolescentes, destacando: 1) Fracturas por estrés o sobreuso, 2) Lesiones del cartílago de crecimiento a nivel de: Fisis y Apófisis, 3) Osteocondrosis y 4) Osteocondritis disecante. Las lesiones musculares no serán motivo de esta revisión.

\section{Fracturas por estrés}

En la edad pediátrica la mayoría ocurre en la adolescencia mediana y tardía( ${ }^{(8)}$, su distribución anatómica depende de la actividad física específica desarrollada y es similar a la de los adultos ${ }^{(9)}$.

Tibia: Es el sitio de más común ocurrencia. Las formas agudas y subagudas aparecen radiográficamente en el hueso cortical como áreas de reabsorción. La reacción periostal adyacente es común y puede ser una manifestación radiológica inicial. Sin embargo, el signo más importante es la esclerosis, debido a reparación osteoblástica. Sólo un 10 a $25 \%$ son radiológicamente detectadas en el inicio de la sintomatología (Figuras $1 \mathrm{a}, \mathrm{b}$ ). 
La cintigrafía ósea trifásica tiene una sensibilidad de $100 \%$ observándose en la primera etapa de la fractura un área focal típica hipercaptante en las 3 fases (Figura 1c). La primera en remitir es la fase angiográfica, hecho que ocurre dentro de las primeras 4 semanas. Sin embargo, la fase esquelética suele permanecer por al menos un año, disminuyendo paulatinamente su intensidad.

La RM es una buena alternativa y es más específica. En secuencia T1 se aprecia una imagen lineal hipointensa y en secuencia T2, especialmente con supresión de grasa y STIR, revelan un área de alta señal, que refleja edema, rodeando una imagen lineal de menor intensidad que corresponde al rasgo de fractura, con el callo adyacente (Figuras $1 \mathrm{~d}, \mathrm{e}$ ).
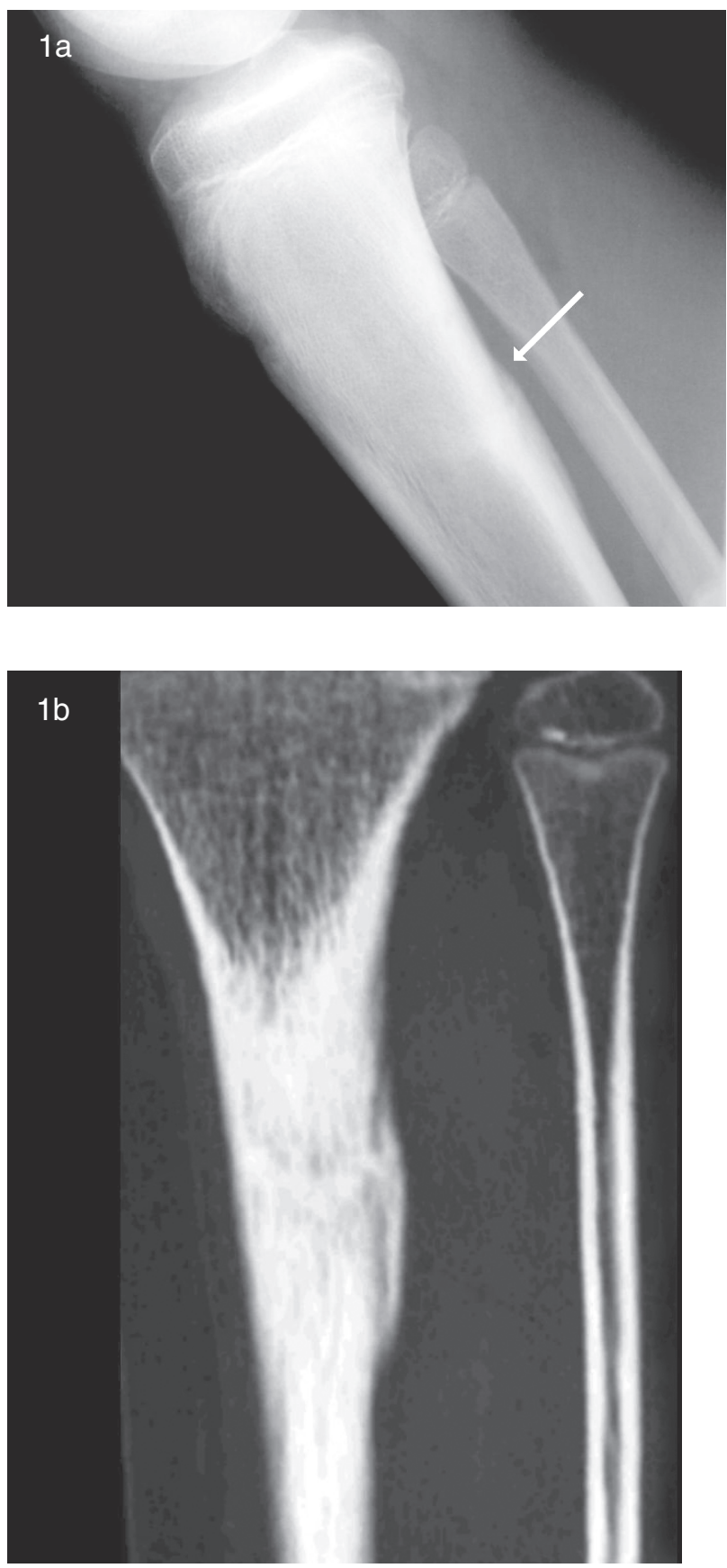
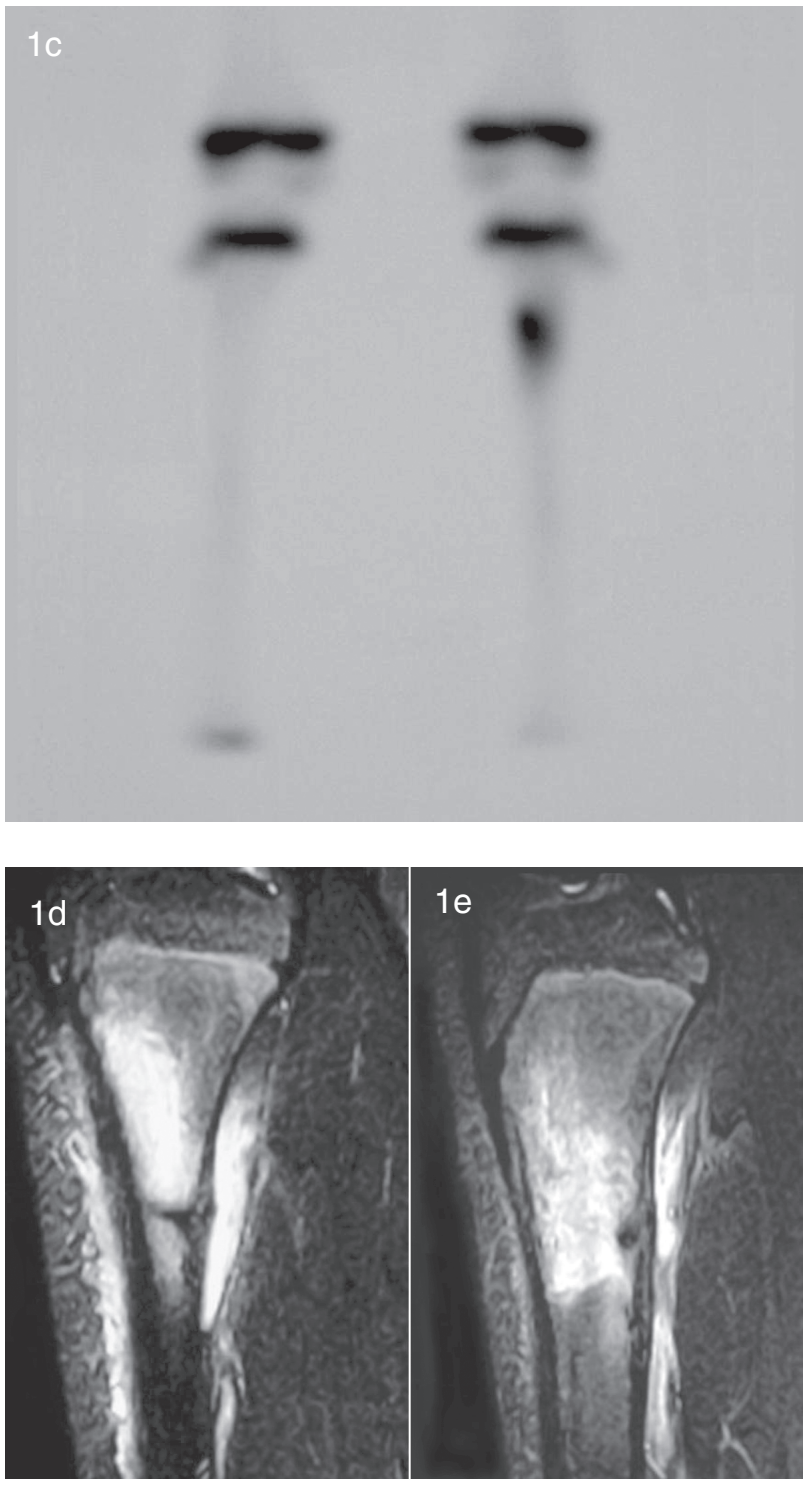

Figura 1 a-e. Fractura por estrés de la tibia. a) Rx de pierna que demuestra esclerosis, reacción periostal y rasgo de fractura en el aspecto posterior de la tibia (flecha). b) TC demostrando fractura por estrés con signos de consolidación. c) Cintigrafía vista anterior mostrando zona hipercaptante en la tibia proximal izquierda. d,e) RM STIR coronal y sagital demostrando edema óseo y fractura visible como imagen lineal hipointensa.

\section{Espondilolisis o fractura de la Pars inter- articularis}

Es más común en niños y adolescentes que en adultos. Es una lesión por sobreuso, asociada con una hiperextensión repetitiva de la columna ${ }^{(10)}$. Se asocia a variadas actividades deportivas, dentro de las cuales puede observarse en gimnastas, bailarines y buzos. El dolor agudo o crónico se agrava durante la extensión y es el síntoma más común con el cual se presenta. Los niveles más frecuentemente afectados son L5-S1 y L4-L5, siendo muy rara en niveles superiores. 
La espondilolisis bilateral puede complicarse con espondilolistesis, que consiste en un desplazamiento anterior del cuerpo de la vértebra involucrada sobre el nivel subyacente. Las proyecciones funcionales, en hiperflexión e hiperextensión, objetivan el grado de anterolistesis.

Las radiografías lateral y oblicuas localizadas a nivel de la unión lumbosacra son muy útiles en demostrar la espondilolisis y la eventual espondilolistesis asociada. La apariencia radiográfica típica es una línea irregular radiolúcida en la pars interarticularis $^{(11)}$ (Figura 2a). También puede existir esclerosis como resultado de reparación de la fractura o remodelación y agrandamiento del pedículo contralateral.

Estas lesiones pueden pasar inadvertidas radiológicamente $y$, frente a una fuerte sospecha clínica, la cintigrafía es un buen método por su gran sensibilidad. La presencia de dolor a nivel de la región lumbar inferior puede ser secundaria a espondilolisis o a una reacción por estrés pre-espondilolisis. En estos casos la cintigrafía demuestra aumento de la captación a nivel de la pars interarticularis y la RM en forma más específica muestra edema sin rasgo de fractura. La tomografía computada (TC) en cortes axiales angulados permite una buena visualización del defecto óseo (Figura 2b, c).

El diagnóstico de espondilolisis por RM puede ser dificultoso y generalmente no se recomienda como examen de primera línea para este propósito.

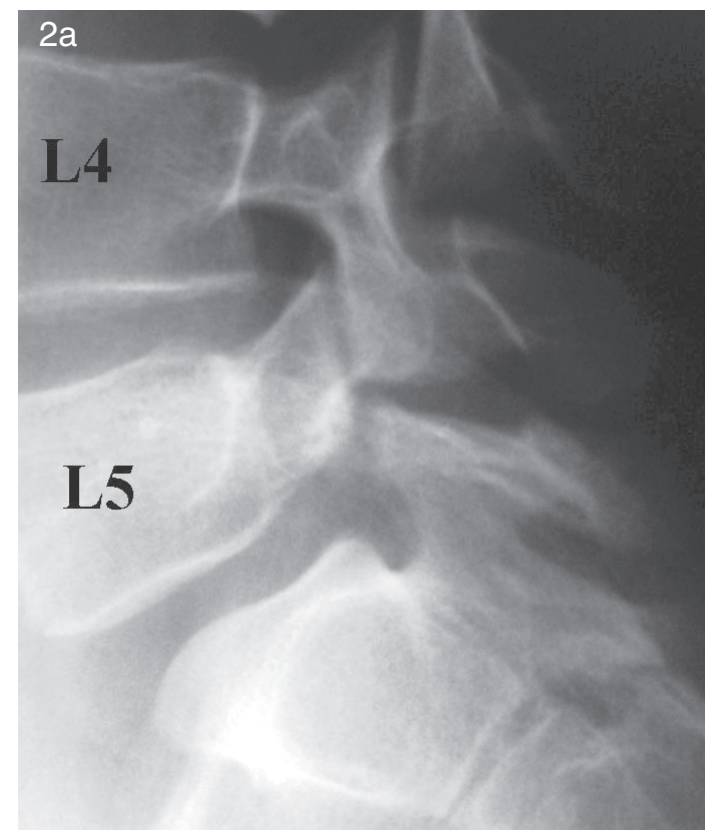

Figura 2 a-c. a) Espondilolisis. Rx lateral de columna lumbar que demuestra solución de continuidad a nivel de la pars interarticular de L5. b) TC reconstrucción sagital que demuestra un rasgo de fractura que cruza la pars interarticularis (flecha). c) Espondilolisis unilateral izquierda. TC corte axial que demuestra fractura unilateral de la pars interarticularis.
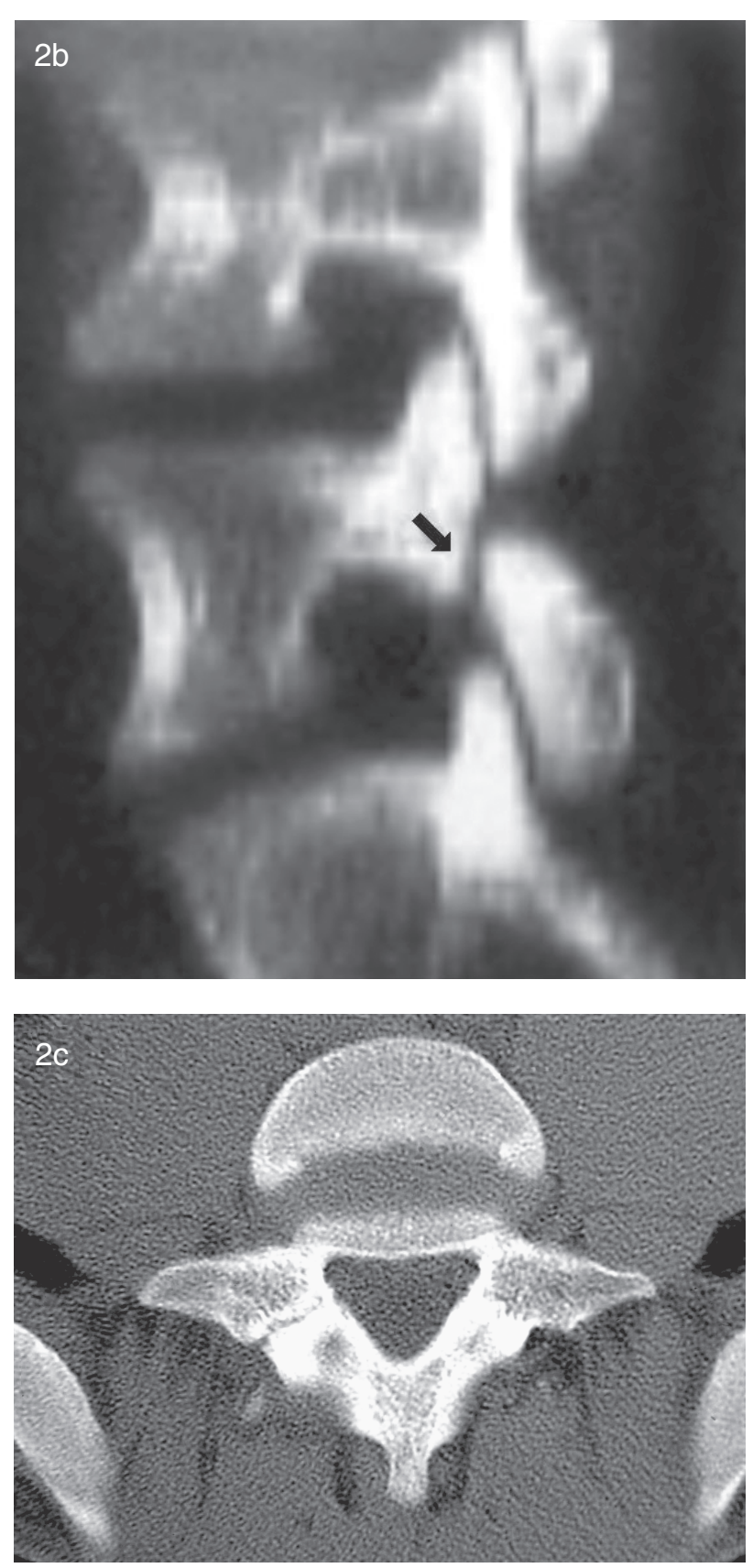

\section{Lesiones del cartílago de crecimiento}

Las lesiones del cartílago de crecimiento pueden afectar la fisis, apófisis ${ }_{\perp}$ así como también los centros de crecimiento epifisiarios.

2a. Fisis: Esta es la porción más débil del esqueleto en crecimiento. Se estima que los ligamentos y las estructuras capsulares que rodean las articulaciones son dos a cinco veces más resistentes que ella durante la adolescencia.

La fisis está compuesta por cuatro zonas. Desde la epífisis a la metafisis están la zona germinal, la zona proliferativa, la zona hipertrófica y la zona de calcificación provisional. Ellas son perpendiculares al eje longitudinal del hueso. Los condrocitos en la fisis forman columnas que se interdigitan dentro de 
la metáfisis. La zona de calcificación provisional es aquella donde las células y su matriz calcifican y es más vulnerable a sufrir lesión. Las fracturas confinadas a esta zona por lo general cicatrizan rápidamente, sin complicaciones. Sin embargo aquellas que se extienden dentro de la zona germinal son propensas a alterar el crecimiento. La distinción no siempre es posible radiológicamente debido a que la línea de fractura puede extenderse hasta ella, particularmente en áreas donde la fisis es ondulada como ocurre en la rodilla. Esto puede explicar por qué las fracturas del tipo I y II en la clasificación de Salter y Harris en estos sitios, pueden llevar a la formación de un puente óseo.

Las lesiones fisiarias pueden resultar por un trauma repetitivo o agudo y son importantes ya que en su cicatrización se pueden formar puentes óseos con la detención resultante del crecimiento y deformidad ósea posterior ${ }^{(12)}$. Analizaremos algunos casos en particular.

\section{Lesión fisiaria del radio distal o muñeca del} gimnasta: El uso de las extremidades superiores para cargar peso en los ejercicios de gimnasia produce una fuerza compresiva excesiva en la fisis del radio distal, por una carga axial repetitiva en extensión produciendo una lesión en este sitio $^{(13)}$. En esta condición existe un dolor que limita la dorsoflexión.

La radiografía puede demostrar un ensanchamiento fisiario irregular (Figura 3a). Ante una radiografía sin hallazgos la RM puede demostrar fracturas horizontales, verticales con extensión del cartílago fisiario hacia la metáfisis y ensanchamiento de la fisis (Figura 3b).

Esta lesión puede producir un cierre temprano con consecuente acortamiento radial y cubito largo secundario que predispone a rotura del complejo del fibrocartílago triangular.

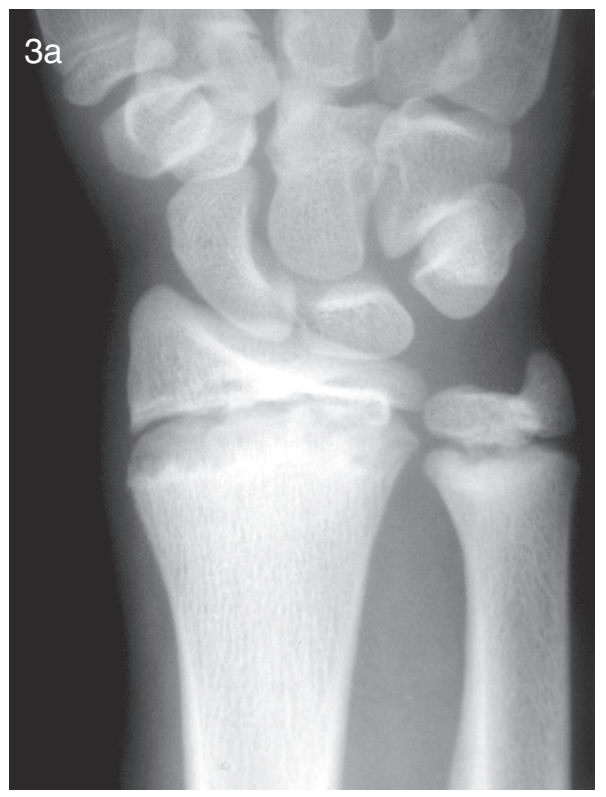

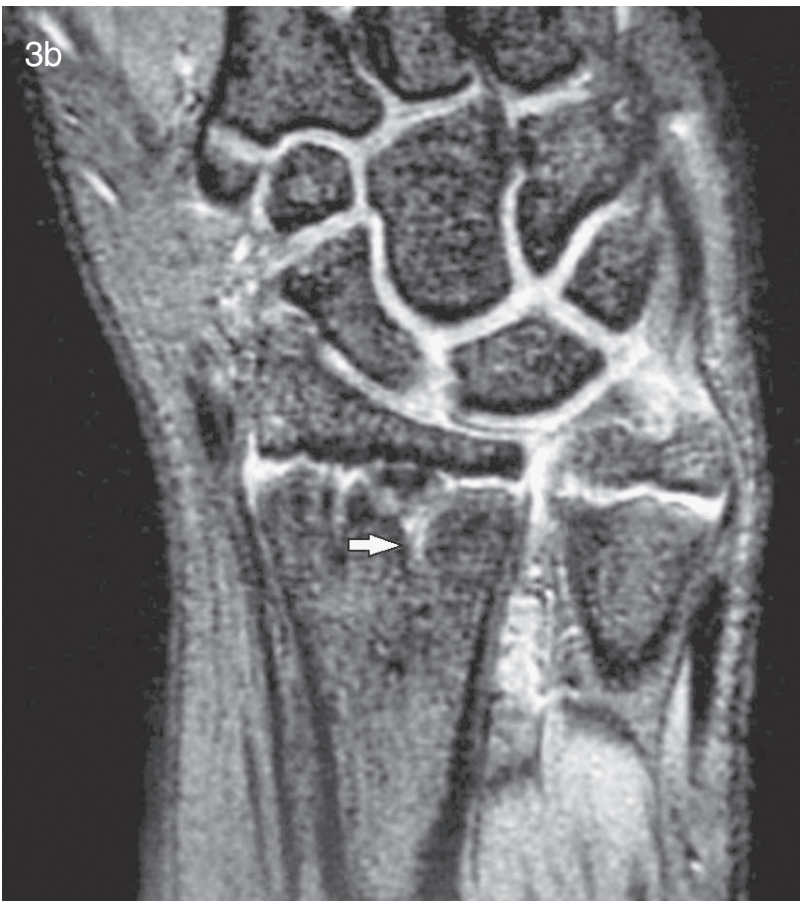

Figura 3 a, b. Muñeca del gimnasta: a) Rx. de muñeca demuestra ensanchamiento e irregularidad de la fisis. $b$ ) $R M$ de la misma paciente demostrando fracturas verticales y extensión del cartílago fisiario dentro de la metafisis (flecha).

Lesión fisiaria del húmero proximal: Se producen por estrés repetitivo en la fisis del húmero proximal. Son secundarias a torsión y valgo repetitivo del húmero. Esta lesión se describe en los lanzadores de pelota en el béisbol y es conocida como "el hombro de la pequeña liga".

Lesión fisiaria del fémur distal: Lesiones agudas en la rodilla afectan la fisis femoral distal, más frecuentemente que la fisis tibial proximal, la cual está particularmente protegida por la inserción de los ligamentos colaterales medial y lateral.

El mecanismo de la lesión es un estrés en valgo agudo o movimiento rotatorio. Aunque constituyen solamente el $2 \%$ de todas las lesiones fisiarias, se asocian en un $40 \%$ a la formación de puentes óseos ${ }^{(14,15,16)}$ (Figura 4).

2b. Apófisis: Las apófisis son regiones cartilaginosas que no contribuyen directamente al crecimiento longitudinal y forman protuberancias donde se insertan los tendones.

La concentración repetitiva de fuerzas tensoras ejercidas por los músculos pueden producir microfracturas o irritación apofisiaria (apofisitis por tracción). Una tracción muscular fuerte y repentina puede producir una avulsión aguda. Esta lesión es una falla estructural del hueso a nivel de la inserción tendínea o aponeurótica ${ }^{(17)}$.

En adultos, después de la completa osificación de las apófisis, estas mismas fuerzas tienden a producir una lesión principalmente musculotendínea. 


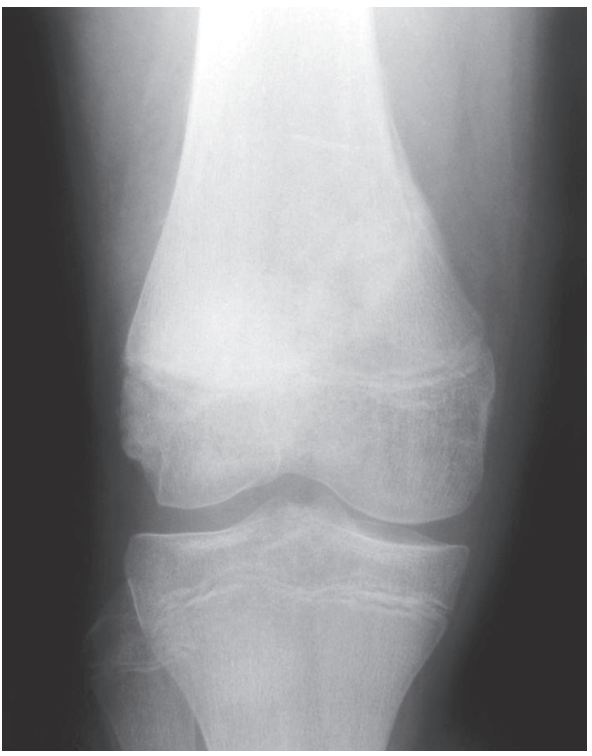

Avulsión o arrancamiento del epicóndilo medial del codo: El epicóndilo medial del húmero es el origen de los flexores pronadores y el ligamento colateral cubital, y es un sitio común de lesión apofisiaria en atletas jóvenes.

Un mecanismo común de lesión se ve en deportistas lanzadores, como por ejemplo el jugador de béisbol, en quien esta lesión se conoce como «codo de la pequeña liga»(18). Durante la fase de aceleración y de lanzamiento se producen fuerzas desde la musculatura flexopronadora que actúan a nivel del epicóndilo medial.

Las avulsiones pueden ser evidentes radiológicamente por separación apofisiaria (Figura 5), pero también pueden ser muy sutiles, con mínimo o sin desplazamiento. En esos casos se recomienda el estudio con RM que puede mostrar edema óseo, ensanchamiento e irregularidad de la fisis epicondilar medial(19). La cintigrafía puede demostrar una asimetría en la captación en relación al epicóndilo medial sintomático, lo que puede sugerir el diagnóstico.

\section{Avulsión del polo inferior de la rótula o «Fractura} en manguito de la rótula»: Ocurre por una contracción rápida y forzada del cuadriceps contra una resistencia por hiperflexión o desaceleración rápida. Se observa en niños entre 9 y 12 años que describen un dolor agudo en la rótula distal. La radiografía lateral muestra un pequeño fragmento óseo que puede asociarse a derrame articular y rótula alta o cabalgada (Figura 6a).

La lesión del cartílago puede ser más extensa que el fragmento óseo avulsionado y no verse radiológicamente. La RM identifica la extensión de la lesión cartilaginosa y delimita el compromiso articular y grado de desplazamiento del fragmento ${ }^{(23)}$ (Figura 6b).
Figura 5.

$R x$ de codo AP que

demuestra

arrancamiento del epicóndilo medial.
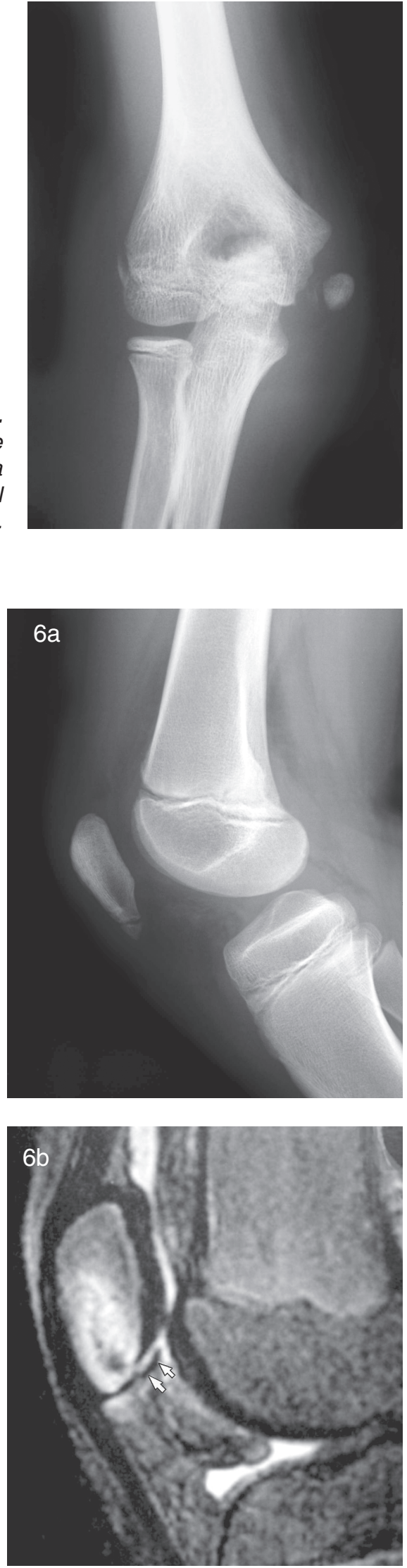

Figura 6 a, b. Avulsión del polo inferior de la rótula. a): $R x$ simple proyección lateral. b) $R M$ de rodilla que demuestra avulsión a nivel del polo inferior de la rótula con un fragmento de cartílago (flechas). 
Otras avulsiones: Apófisis de la extremidad superior del cuerpo que ocasionalmente sufren lesiones similares son el olécranon, la coracoides y el acromion.

Lesiones de la apófisis del cuerpo vertebral pueden permitir salida del material discal a través de ella y provocar separación de un pequeño fragmento óseo en el borde antero superior, generalmente a nivel lumbar.

Avulsiones en la pelvis y apófisis femorales proximales son lesiones comunes durante la infancia y adolescencia(20) (Figura 7). Los centros de osificación apofisiaria de la pelvis y del fémur proximal son varios. Los músculos que se unen a estas apófisis a través de sus tendones incluyen: en cresta ilíaca la musculatura de la pared abdominal; en espina ilíaca anterosuperior, el sartorio y tensor de la fascia lata; en la espina ilíaca anteroinferior el recto femoral; en el isquión los isquiotibiales y aductores; en el trocánter menor el iliopsoas y en el trocánter mayor los rotadores externos de la cadera.

Las avulsiones de las apófisis pelvianas y del fémur proximal son más comunes en velocistas, jugadores de fútbol, bailarinas de ballet y saltadores. Debe sospecharse en adolescentes con dolor en la cadera y región dorsal baja. La sintomatología se describe típicamente como un dolor de comienzo brusco durante una actividad forzada. EI desplazamiento de la apófisis es generalmente visible radiológicamente, salvo algunos casos en que el fragmento avulsionado es completamente cartilaginoso(21).

En los arrancamientos crónicos puede existir formación de un callo óseo exuberante que puede confundirse con una lesión maligna ${ }^{(22)}$. En estos casos la TC o RM puede ser útil para el diagnóstico diferencial.

Las avulsiones de la cresta ilíaca pueden tener poco desplazamiento y no ser detectadas radiológicamente. En estos casos la cintigrafía ósea y la RM son los estudios de elección. En algunos casos la US es de utilidad (Figura 8).

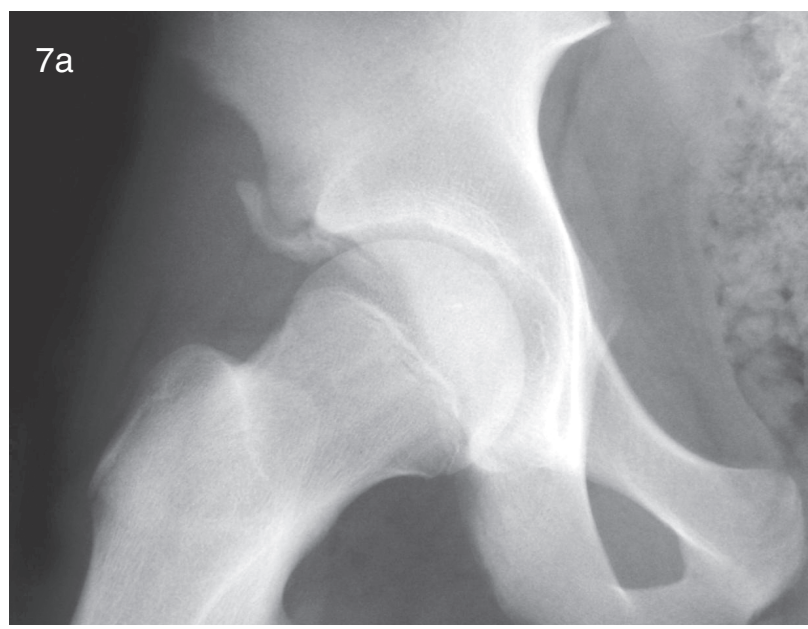

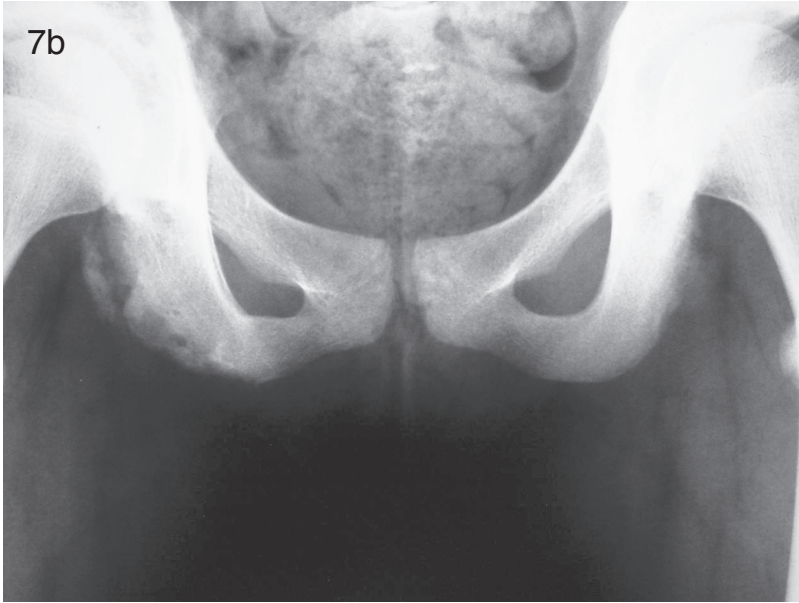

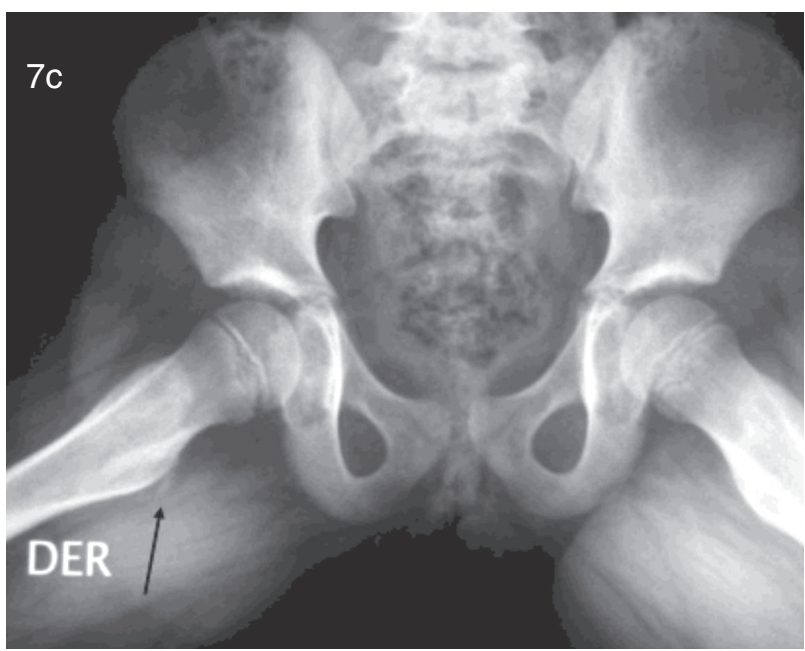

Figura 7 a-c. Radiografías simples de pelvis. a) Arrancamiento de espina ilíaca antero-inferior. b) Arrancamiento a nivel del isquión a derecha. c) Arrancamiento del trocánter menor del fémur derecho.

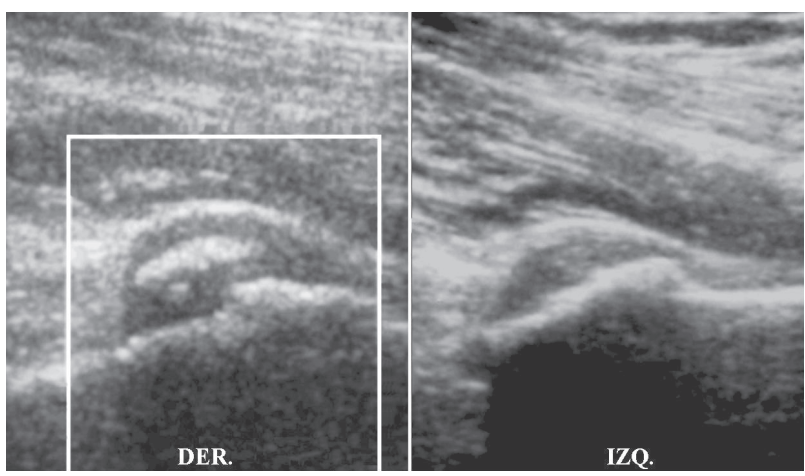

Figura 8. US de trocánteres menores demostrando fragmento avulsionado a derecha como línea ecogénica. Se compara con lado izquierdo normal.

\section{Osteocondrosis}

Son lesiones frecuentes en atletas jóvenes y predominan a nivel de la articulación de la rodilla.

Enfermedad de Sinding-Larsen-Johannson. Es común entre las edades de 10 a 12 años. La tracción repetitiva por el tendón rotuliano puede producir una 
calcificación u osificación irregular del polo inferior de la rótula. El dolor que provoca se asocia típicamente con actividades como correr, escalar, subir escaleras o arrodillarse (Figura 9).

Las lesiones agudas y crónicas de la unión del cuadriceps a la rótula proximal también pueden ocurrir, pero son infrecuentes en el niño.

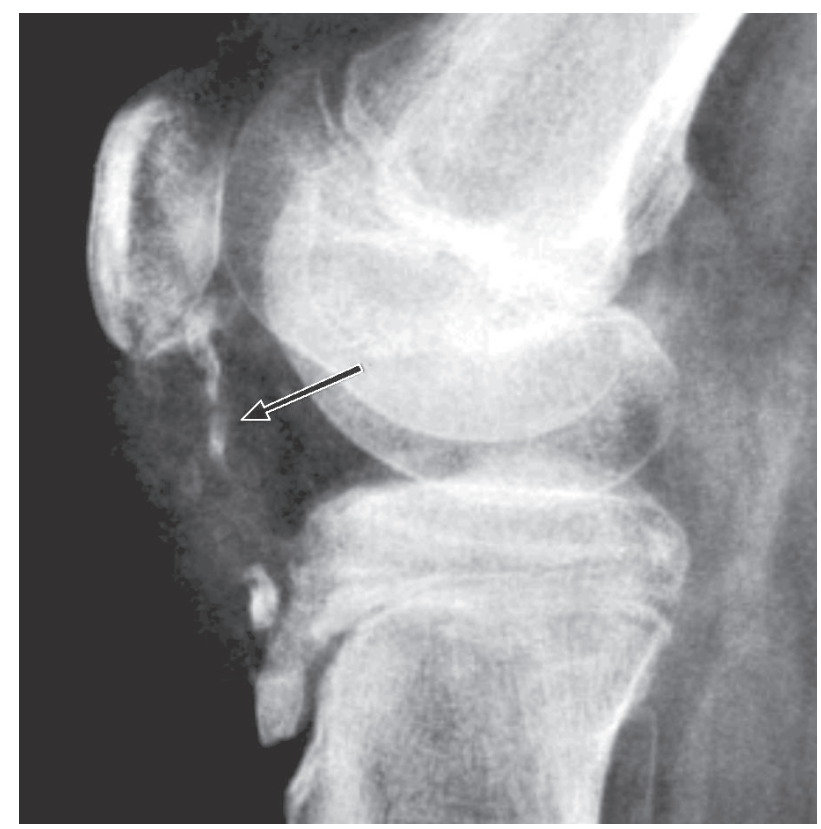

Figura 9. Enfermedad de Sinding-Larsen-Johannson. $R x$. de rodilla demuestra calcificación del tendón rotuliano.

Enfermedad de Osgood Schlatter: La tuberosidad anterior de la tibia es una extensión condral de la epífisis proximal. Se desarrolla como un centro secundario de osificación entre los 7 y los 9 años. Se fusiona entre los 13 y los 15 años en niñas y entre los 15 y los 19 años en hombres.

La enfermedad de Osgood Schlatter es una lesión por tracción repetitiva del tubérculo tibial por el cuadriceps, vía tendón rotuliano, caracterizada por dolor local, edema y sensibilidad; se observa frecuentemente entre los 10 y 15 años de edad.

El diagnóstico se establece clínicamente. Las imágenes, incluyendo la radiografía, RM y cintigrafía, se realizan para excluir otras patologías. La radiografía revela edema de los tejidos blandos anteriores a la tuberosidad tibial, engrosamiento del tendón rotuliano y borramiento de la grasa infrarotuliana (Figura 10).

Los hallazgos en la RM incluyen una señal aumentada en secuencias potenciadas en T2 a nivel de: tendón rotuliano, su inserción en el tubérculo tibial, tejido blando que lo rodea y en médula ósea(24).

La cintigrafía muestra asimetría en la captación del radiofármaco a nivel de las tuberosidades.

Puede haber osificación irregular y fragmentada de la tuberosidad, que en ausencia de síntomas debe considerarse una variante normal.

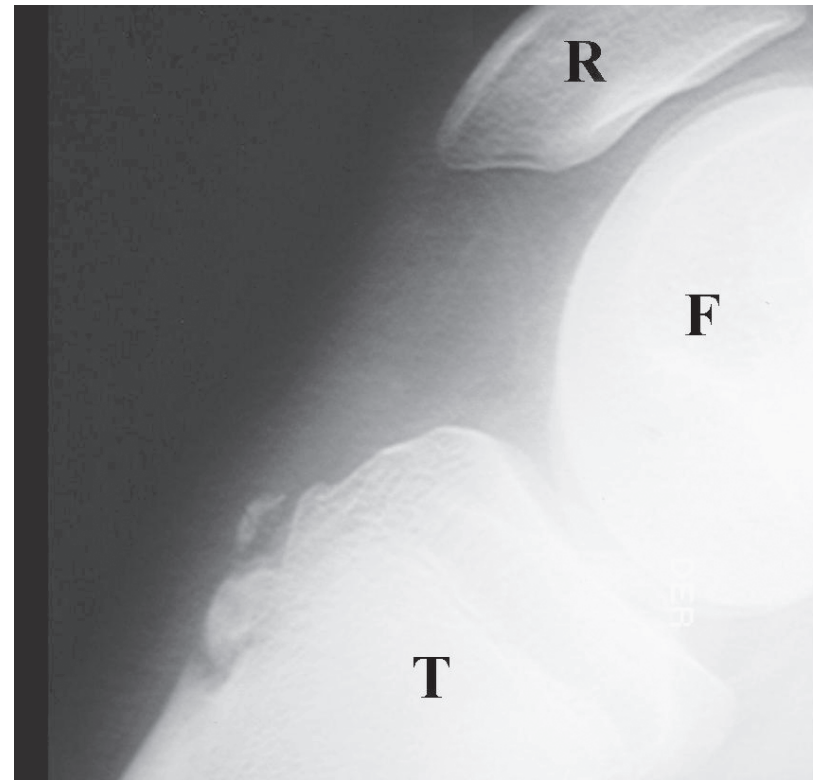

Figura 10. Enfermedad de Osgood Schlatter. Rx. de rodilla lateral que demuestra fragmentación del núcleo de osificación de la tuberosidad anterior de la tibia asociada a aumento de volumen de las partes blandas. R: Rótula. F: Fémur. T: Tibia.

\section{Enfermedad de Panner u Osteocondrosis} capitelar traumática: Son lesiones del capitelum cuando está incompletamente osificado, antes de los 10 años de edad.

A diferencia de la osteocondritis, es poco frecuente que en ella ocurra la formación de cuerpos libres y deformidad residual.

Los hallazgos radiológicos son: aumento de la densidad, fragmentación, fisura y reabsorción del capitelum (Figura $11 \mathrm{a}, \mathrm{b}$ ). Las imágenes de RM pueden revelar fragmentación y disminución de la señal de intensidad en T1 a nivel del centro de osificación del capitelum (Figura 11c).

Figura $11 a$.

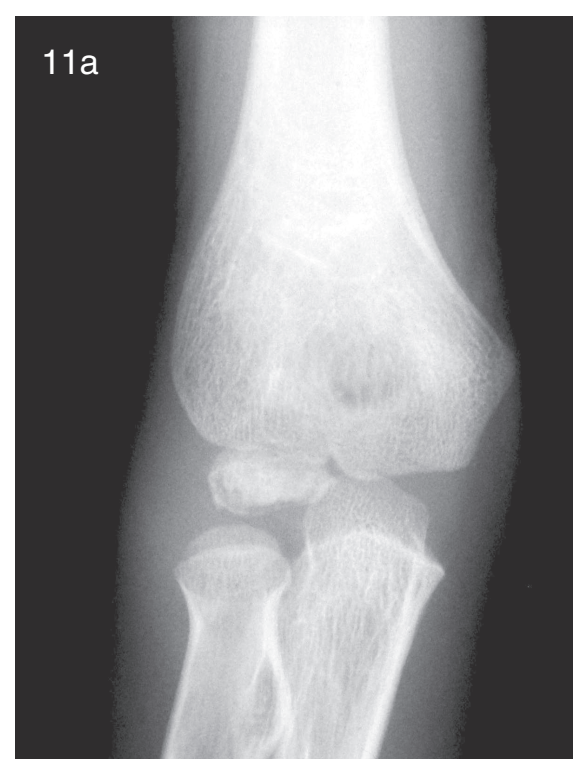



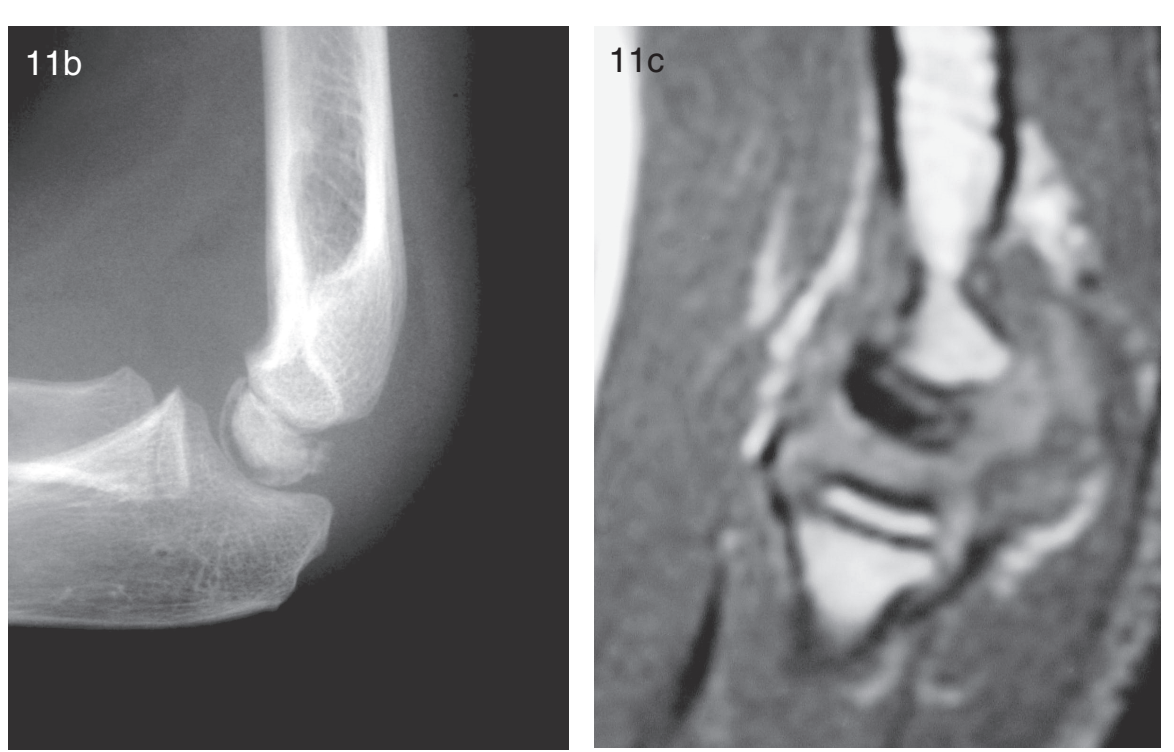

Figura 11 a-c. Enfermedad de Panner. a,b) Rx simple AP y lateral en donde se observa aumento de la densidad, fragmentación y reabsorción subcondral a nivel del capitelum. c) RM ponderada en T1 demostrando disminución de la intensidad de señal a nivel del capitelum.

\section{Osteocondritis disecante}

Aunque la exacta etiopatogenia no está del todo clara, la principal hipótesis propone que es provocada por fuerzas compresivas y repetitivas en una epífisis inmadura, que producen fragmentación y a veces separación de una pequeña parte de la superficie articular.

Afecta principalmente a adolescentes y los sitios comunes son el capitelum o cóndilo lateral del húmero, cóndilos femorales y astrágalo. Los varones presentan una mayor predisposición.

\section{Osteocondritis disecante del capitelum o cóndilo} lateral: Se cree que es el resultado de una compresión repetitiva en valgo más tracción. Se ve en jugadores de béisbol, gimnastas y jugadores de básquetbol.

La radiografía puede revelar osificación irregular, fragmentación del capitelum o un defecto radiolúcido (Figura 12a).

La RM puede mostrar aplanamiento anterior del capitelum, necrosis subcondral, líquido articular, fragmentos y separación de fragmentos osteocondrales (Figura 12b).

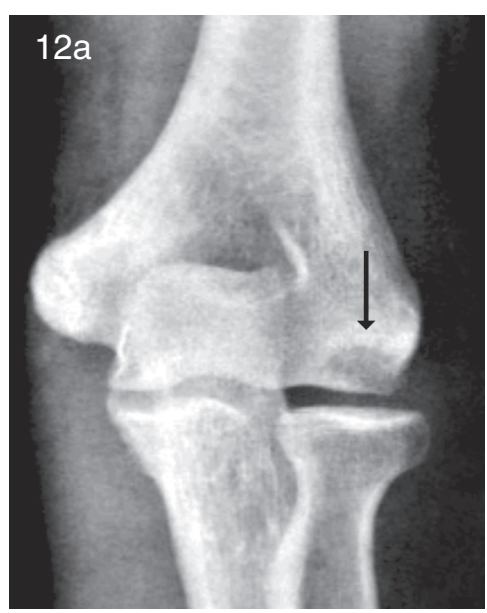

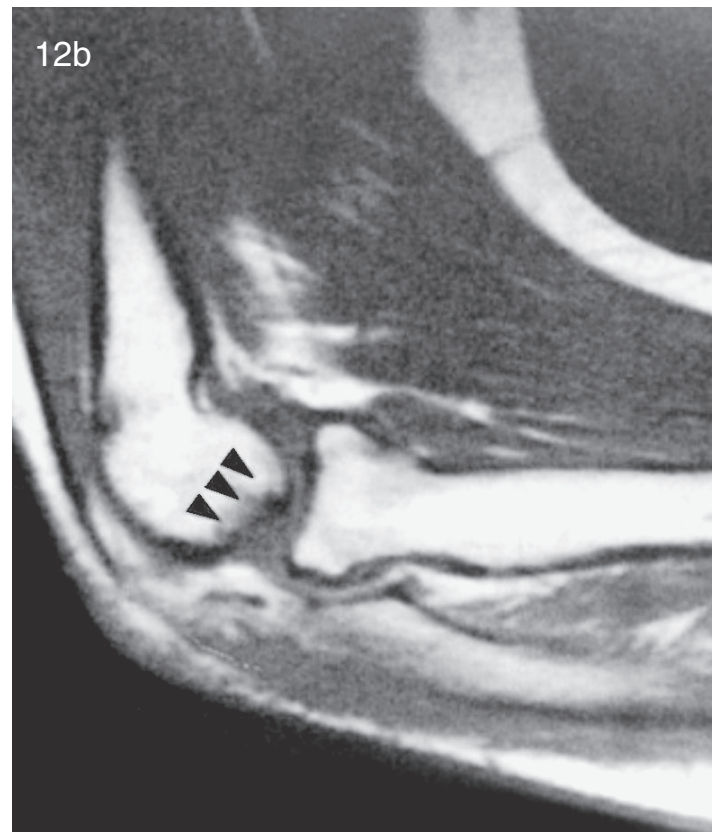

Figura 12 a, b. Osteocondritis disecante del codo (capitelum). a) $R x$ simple demostrando defecto radiolúcido del capitelum. b) RM demostrando aplanamiento e irregularidad del capitelum (flechas).

Osteocondritis disecante del cóndilo femoral: Compromete principalmente la región posterolateral del cóndilo femoral medial. Cerca de un tercio de los casos son bilaterales.

El mecanismo de la lesión es desconocido, aunque ha sido relacionada tanto a microtrauma como un evento traumático agudo.

Radiográficamente la lesión clásica es vista como un fragmento óseo con un interfase radiolúcida. Hay frecuentemente esclerosis adyacente ${ }^{(25)}$.

Las imágenes en RM juegan un rol en establecer el compromiso del cartílago articular, tratando de definir la naturaleza estable o inestable de la 
lesión ${ }^{(26)}$. La presencia de líquido entre el fragmento y el hueso adyacente indica disrupción del cartílago y por tanto inestabilidad de la lesión. Fragmentos desplazados a la cavidad articular pueden ser evidentes en RM.

Osteocondritis del astrágalo: Ocurre en la superficie medial y posterior de la cúpula astragalina, siendo también observada en la lateral y central, y es el resultado de un impacto más torsión.

Los hallazgos radiológicos y de RM son similares a los descritos en el fémur distal (Figura 13). Debido a que los cartílagos en la articulación tibio-astragalina son de menor grosor, su evaluación es más difícil.
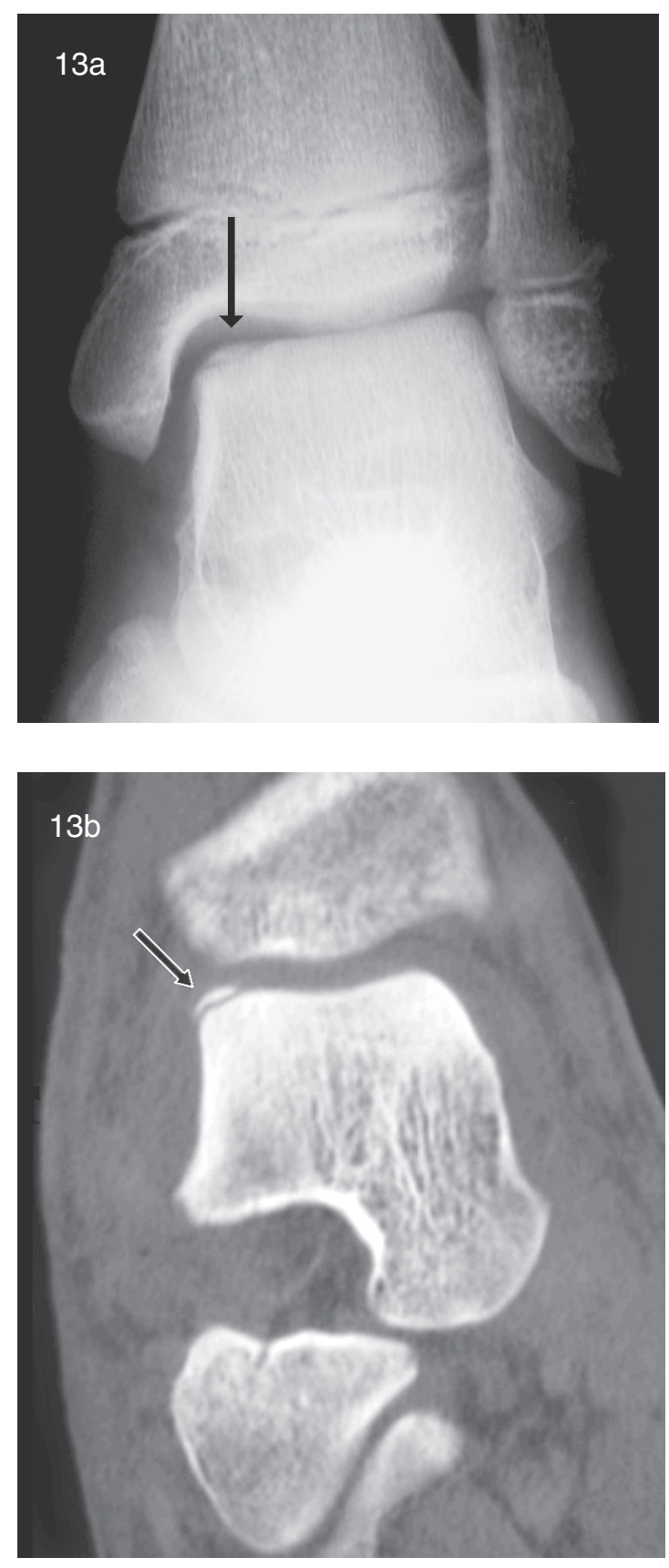

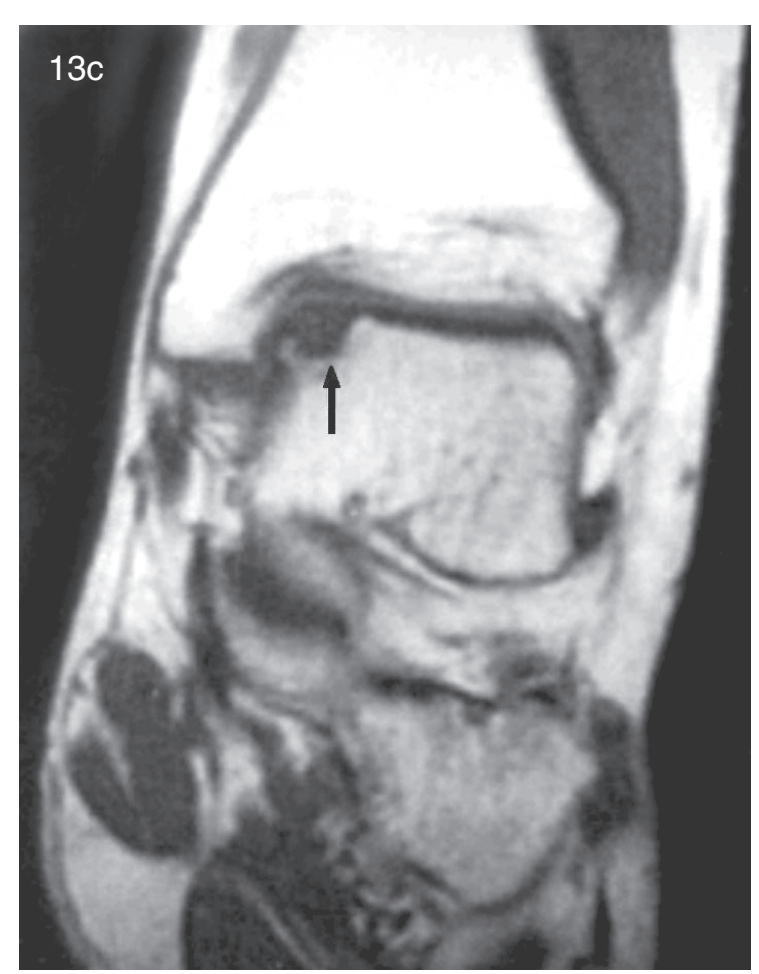

Figura 13 a-c. Osteocondritis disecante del astrágalo. Fragmento óseo a nivel de la cúpula astragalina medial. a) $R x$ simple. b) $T C$ c) $R M$.

\section{Conclusión}

Las lesiones osteoarticulares relacionadas con la actividad deportiva competitiva son frecuentes en la niñez y adolescencia. El diagnóstico por imágenes es esencial en muchas de ellas, y el método para evaluarlas dependerá de cada caso y lesión en particular.

\section{Bibliografía}

1. Carty H. Children's sports injuries. Eur J Radiol 1998; 26: 163-176.

2. Landry GL. Sport injuries in childhood. Pediatr. Ann 1992; 21:165-168.

3. Loor T, Jaramillo D, Oestreich AE. Musculoskeletal system. In: Kirks DR, Griscom NT, eds. Practical pediatric radiology of infants and children. 3 edition Philadelphia. Pa. Lippincott Raven, 1998; 327-510.

4. Resnick D. Physial injury concept and terminology. In: Resnick D, Ed. Diagnosis of bone and join disorders. 3 editions. Philadelphia, Pa. Saunders, 1995; 25612692.

5. Buckley SL. Sport injuries in children. Curr Opin Pediatr 1994; 6: 80-84.

6. Chan D, Aldridge MJ, Maffulli N, Davies AM. Chronics stress injuries of the elbow in young gymnasts. $\mathrm{Br} \mathrm{J}$ Radiol 1991; 64: 1113-1118.

7. Micheli LJ. Overuse injuries in children's sport. The growth factor. Orthop Clin North Am 1983; 14: $337-$ 360.

8. Coady CM, Micheli LJ. Stress fracture in pediatric athlete. Clin Sport Med 1997; 16: 225-238. 
9. Mc Bryde AM. Stress fracture in athletes. J Sports Med 1975; 3: 212-217.

10. Hession PR, Butt WP. Imaging of spondylolysis and spondylolisthesis Eur Radiol 1996; 6: 284-290.

11. Bellah RD, Summerville DA, Treves ST, Micheli LJ. Low back pain in adolescent athletes. Detection of stress injury to the pars interarticularis with SPECT. Radiology 1991; 180: 509-512.

12. Peterson HA. Physeal and apophyseal injuries. In: Rockwood. CA. Jr, Wilkins KE, Beary JH, eds. Fractures in children 4 edition Philadelphia, PA. Lippincott Raven. 1996; 103-165.

13. Carter SR, Aldridge MJ, Fitzgerald R, Davies AM. Stress changes of the wrist in adolescent gymnasts. Br J Radiol 1988;61:109-112.

14. Kasser JR. Physeal bar resections after growth arrest about the knee. Clin Orthop 1990; 255: 68-74.

15. Craig JG, Cramer KE, Cody DD, et al. Premature partial closure and other deformities of the growth plate. MR imaging and three dimensional modeling. Radiology 1992; 210: 835-843.

16. Young JW, Bright RW, Whitley N. CT in the evaluation of partial growth plate arrest in children Skeletal Radiol 1986;15: 530-535.

17. Tehranzadeh J. The spectrum of avulsion and avulsion like injuries of the musculoskeletal system. Radiographics 1987;7: 945-974.

18. Brogden BG, Crow NE. Little Leaguers elbow. AJR 1960; 83: 671-674.
19. Rogers L. Fractures and dislocations of the elbow. Semin Roentgenol 1978; 13: 97-107.

20. Sundor M, Carty H. Avulsion fracture of the pelvic in children a report of 32 fractures and their outcome. Skeletal Radiol 1994; 23: 85-95.

21. Rossi F, Dragoni S. Acute avulsion fractures of the pelvis in adolescent competitive athletes. Skeletal Radio 2001; 30: 127-131.

22. Donnelly LF, Bisset GS, Helms CA, Squire DI. Chronic avulsive injuries of childhood. Skeletal Radiol 1999; 28:138-144.

23. Vellet D. Magnetic Resonance imaging of bone marrow and osteochondral injury. Magn Reson Imaging. Clin N Am 1994; 2: 413-423.

24. Rosenberg CS, Kawelblum M, Cheung YY. Osgood Schlatter lesion fracture or tendinitis. Scintigraphic, CT, and MR imaging features. Radiology 1992; 185: 853858.

25. Milgram J. Radiological and pathological manifestation of osteochondritis dissecans of the distal femur. Radiology 1978; 126: 305.

26. De Smet A, Fisher DA, Graf BK, Lange RH. Osteochondritis disecans of the knee. Value of MR imaging in determining lesion stability and the presence of articular cartilage defect. Am J Roentgenol AJR 1990; 155: 549-553.

27. Ozonoff M. The lower extremity. In: Pediatric orthopaedic radiology. 2 edition. Philadelphia, $\mathrm{Pa}$. Saunders 1992; páginas 304-396. 